\title{
The Case for BIM Uptake among Small Construction Contracting Businesses
}

\author{
P. Forsythe ${ }^{a}$ \\ ${ }^{a}$ School of the Built Environment, University of Technology Sydney, Australia \\ E-mail: Perry.Forsythe@uts.edu.au
}

\begin{abstract}
-
Advocates of BIM have the ambition of making it a central tool for information management and collaboration among stakeholders on construction projects. Even so, its implementation is often difficult for small construction contracting businesses, albeit that they make up such a large proportion of the construction industry. This paper uses data from a targeted workshop of 47 industry professionals concerning issues in transitioning from traditional to BIM based construction project management and the impact of BIM on professional training and development. The findings support the proposition that BIM uptake in construction contracting is relatively low and that small contracting businesses currently constitute the weakest link in BIM based supply chains. In order to realise the full potential of BIM, there is a greater need to make it accessible to small businesses but forced uptake is not recommended. Practical difficulties include software application costs, the need for multi-tasking, risk management issues, and confusion over the type of skilled people and training needed for operating BIM software. A "touch the BIM lightly" approach is advocated as is the development of stylised BIM applications targeted to better suit the capabilities of small construction contracting businesses, as distinct from design authoring businesses. Greater attention should be placed on low learning time, low cost, site-tasks and one-way information flows. All such recommendations are consistent with implementation using smartphone and tablet technology.
\end{abstract}

\section{Keywords -}

BIM; small business, construction contracting

\section{Introduction}

BIM can be defined as the "modelling technology and associated processes to produce, communicate, and analyse building models" [1 P.16].
Nowadays, the literature spans broadly on this topic and examples of the following technical themes figure strongly in the literature: interoperability [2]; construction safety [3]; lean production [4]; conflict reduction [5]; sustainable design [6]; 4D construction scheduling [7]; conformance modelling [8]; 5D cost estimating[9], integrated process implementation [10] and project management [11].

Other efforts have focused more specifically on how people and organisations interact with BIM technology. Instances include BIM as a collaboration platform [12], as a procurement framework [13], as a tool in supply chains management [14] and in the multi-disciplinary expectations of participants involved in construction projects [15].

Despite the potential benefits of BIM, there is still concern about the slowness of its uptake in industry. For instance, authors such as Bew and Underwood [16] who have been instrumental in the UK implementation of BIM (see for example http://www.doi.org/doi_handbook/1_Introduction.html), identify that for an organisation to implement BIM it must be collaborative across the entire supply chain but it must concurrently make sense for businesses to be involved in such technology; it must be realistic relative to that business's current capabilities. Here, the ideal situation is that a virtual information model will be handed from the design team through the supply chain and then to the client on completion [17]. Even so, such a scenario is only as strong as its weakest link. Unfortunately, in the Australian construction industry there seems to be relatively little BIM penetration beyond the design stage of a project and especially when moving down the supply chain where it is common to find smaller construction contracting businesses involved. It is felt this hurdle to BIM uptake has yet to be fully explored and therefore this research studies the plight of small construction contracting (and subcontracting) businesses in the context of BIM uptake in Australia.

\section{What Does Small business mean}

Authors such as Clifford et al [18] identify that size, 
structure and self governance are important aspects of describing small business. To this end, they propose that small business can be defined in terms of an employee range from 8 to 50 people but qualify this by stating that the lower end of the range maybe characterised by owner operators, the mid-range by owner managers and the upper range by owner directors.

Despite the contextual relevance of the above, it would still seem that "number of employees" dominates the main key criteria used to define small businesses [19]. For instance in Australia, the Australian Bureau of Statistics defines small businesses as having 19 employees or less and defines micro businesses as having 4 employees or less [20].

With this in-mind, $47.7 \%$ of the Australian construction industry involve small businesses based on value added terms [20] and $63 \%$ of employment in the sector comes from small businesses [20]. Clearly, small businesses have a large impact on the construction industry.

In probing further, approximately two-thirds $(67.0 \%)$ of these workers exist within construction services including the likes of bricklaying, plumbing, concreting, roofing services, structural steel erection, electrical services, air-conditioning services, fire and security alarm installation services, plastering, carpentry services and glazing [20-21].

In this area, small businesses represent a huge $97.8 \%$ of the construction services sector [20]. This is not a feature limited to Australia, as similar situations exist in the likes of the UK[22], the United States [23] and Asia as well [24].

In analysing the literature specific to the implementation of BIM in small businesses, most of it relates to the slightly broader category of small to medium enterprises (SMEs). Here, Gledson et al's [25] study of middle to senior level managers confirms that significant differences exist between the large versus SME scale businesses. One aspect they identify is whether or not the proposed savings from BIM will be passed down the supply chain. Another concerns the degree of multitasking among SME staff relative to more dedicated functional roles in larger businesses hence limiting the ability to provide dedicated BIM staff in SMEs. More generally they cite cultural, legal and commercial barriers as features impeding BIM uptake in SMEs relative to larger businesses - a view supported by other authors such as Yan and Damien [26] on cultural barriers, Sebastian [17] on commercial barriers, Greenwood et al [27] on legal barriers, and Takim et al [28] on software licencing costs. Oluwole [29] goes further on this last issue by stating that software costs can account for as much as 55 percent of total BIM implementation costs.

Others delve deeper into the specifics of people oriented issues within construction related businesses. For instance , Arayici and Coates [30]and Arayici et al [31] found that BIM implementation was impeded in design practices by a lack of operational skills, staff training and the additional layer of complexity posed in understanding BIM specific protocols and standards. Anderson et al. [32] found that BIM is perceived as being difficult to access, may not be trustworthy and may not necessarily be neutral insofar as information being created and controlled by others. Harris et al's [33] large scale study of SMEs found that incremental levels of innovation were possible where there was an emphasis on people or organic aspects of BIM and TQM, as distinct from more mechanistic approaches to implementation. Even so, there was still no clear link between such technologies and radical levels of innovation.

Given the above, it is not surprising that Porwal and Hewage [13] assert that organizational and people centred issues pose the greatest challenge for BIM implementation and that contractors must be integrated as early as possible in the design phase for BIM to have a strong impact on project outcomes.

What can be gleaned from the above is simply that the technology intensive nature of BIM appears to be particularly difficult in terms of people issues and this is exacerbated further when taken in the context of small businesses. As raised earlier in the paper, this research focuses upon gaining a better understanding of the extent to which such issues impact on small construction contracting businesses in Australia. This aims to underpin and direct discussion about the best way forward in assisting stronger engagement concerning BIM uptake (across the entire supply chain).

\section{Research method}

In addressing the above, a large industry workshop on the implications of BIM on future professional needs was undertaken as a mechanism for feedback and consensus concerning BIM uptake. Whilst the workshop covered a variety of issues, only those implicating the perspective of small construction contracting businesses (including subcontracting) have been reported in the findings.

In total, 47 middle to executive level managers participated in the workshop with representation predominately consisting of architectural firms, specialist design consultants, quantity surveyors, head contractors and subcontractors.

The structure of the workshop began with formal yet brief presentations from a small group of speakers covering cogent topics of relevance to industry uptake. This was used to set the tone for debate during the ensuing breakout sessions which focused on 
transitioning from traditional to digitally based construction project management, and posing key questions such as the most important issues arising from BIM in practice, and the associated impacts of these changes on professional training and development.

In executing the breakout sessions, participants were directed into special interest subgroups covering different disciplinary roles such as construction technology, structures, services, procurement, design management, time management, cost management and urban design. Each group debated the abovementioned issues and then reported back their key findings and conclusions. This approach provided a direct account of the plight of construction contractors in BIM uptake, and also provided the way that others in the supply chain viewed the uptake of BIM by such contractors.

The discussion arising from the breakout sessions was transcribed and then a thematic analysis was undertaken to derive the main perceptions and ongoing issues of relevance. Here, thematic analysis serves to process raw qualitative data into categories of thematic meaning. It is similar to content analysis but the focus is on categorising theme frequency rather than word frequency. Promotion of the deeper level of meaning contained in themes (as opposed to words) has been acknowledged as far back as Cicourel [34] and its more modern implementation is elaborated upon in detail by qualitative researchers such as Boyatzis [35].

The findings are discussed in terms of the main themes identified from the analysis and are supported by indicative quotes from different participants made during the breakout sessions (as shown in italics).

\section{Analysis and findings}

The findings arising from the study extend and add further context to themes reported previously in the literature review. At an over-arching level, it was apparent that contracting businesses in general were perceived as having relatively low uptake of BIM on building construction projects. This especially appears to be the case where involving small subcontract businesses e.g. "A lot of them say, what is BIM, what does that mean?" and, "That's our problem, as a constructor, there's no subbies (sub-contractors) engaged in this sort of stuff. We need to get them engaged. Sure there's a whole heap of architects here and probably some structural guys, but as a constructor we are finding that the subbies are very much behind the eight ball".

These and related issues lead to the perception that construction contractors have a tendency to inflate their tender prices to undertake BIM based construction work e.g. "Now some of the contractors actually inflate their tender because of BIM. They're saying, if you want a
BIM model, we will charge you $\$ 100 K$ more, or something like that"

Consistent with the above, it was perceived that there was a gap in knowledge that effects subcontractors more than most e.g. "So collaborations with subcontractors and narrowing the gap of knowledge, or working out ways to help companies that might not be at the required level - how do we bring those people up to speed?"

In delving deeper into the day-to-day operations of construction contractors' onsite, there was the view that spending large amounts of time and resources interrogating a BIM to extract construction specific information was not an option for them. They felt that they did not have the skills to interact with the BIM; dealing with the BIM was an extra cost to production; the BIM is often large and unwieldy in terms of the information that subcontractors need to extract from it e.g. "If you're down the pecking order at a subcontractor level, you don't necessarily want to see, or you want to very quickly drill down to the bits (of information) you need to know.".

A similar view was apparent in terms of BIM usage in work flow scheduling. Here, the dominance of the traditional Gantt chart was not underestimated and reflects the level of technology that is commonly used by construction contractors, as captured below:

Unfortunately, the Gantt chart has been run for half a century and we're still using it.

We don't want something high-tech and we don't need something more complicated than the critical path method.

(With reference to BIM) Not because people don't want to change but because people don't want to change for complication. We want efficiency. We want something simple on the construction site. So, hopefully, BIM as the new technology could provide the solution.

Despite the above, some have had a degree of success by stylising interaction with the BIM (mainly the $3 \mathrm{D}$ view of the model) in a way that was simplified and well tailored to meet onsite needs using the likes of laptop technology e.g. "They want a laptop of the model, with a viewer onsite. They've done that and I think it's been giving them huge benefits, in terms of onsite understanding."

From the above, it would seem that in order to optimise BIM across the supply chain, it may be worth re-thinking specific aspects of implementation to suit organisational size and capability. Here attention must 
be given to small construction subcontracting organisations and targeting a specific level of involvement for them that will be both viable and will allow the efficiency of the supply chain to improve overall.

\subsection{BIM Advocacy and the impact on construction contractors}

It was apparent from the breakout groups that BIM advocacy was stronger among design professionals than construction contractors. Clearly, the sophistication of BIM usage among design professionals (e.g. architects, structural engineers, mechanical engineers) was linked to their long term affinity with digitally based tools for communicating and documenting design information on projects. It was also evident that this advocacy would inevitably impact on construction contractors - as captured in the following quotations:

I think we're going to see a marked division in the industry of the people who have adopted BIM processes and the ones that have not.

I'd really like for it to be (mandatory) because architects have technical capabilities.

Giving people no choice (about the use of BIM) is a great way of getting them into this process.

I think it all comes back to collaborating again and unfortunately we're getting a complete lack of models from certain parts of our industry. We would also love to see the contractors getting involved much earlier.

A contractor may not be ready for construction sequencing using BIM or location-based analysis, even cost estimation. But everybody can see and understand clash detection and it just saves money very, very directly.

I think one of the important issues surrounding people issues is that very soon you are finding BIM model managers taking over the role as your traditional contract managers, and perhaps rightfully so, because they are the key holders to all the important information.

A key issue arising from the above (and consistent with previous discussion) is simply that small construction contractors seem to represent the weakest link in the BIM based supply chain on projects. A question arising from this concerns what is the appropriate level of BIM uptake for such businesses including, is it best to force change, or advocate for a more mediated approach based around incremental uptake of the technology.

\subsection{Fast moving technology versus trying to keep up}

Unsurprisingly and adding to the previous point, a key theme from the workshop concerned the rapid evolution of BIM technologies and the ability of the supply chain to keep up. The basic tenets of 3D technology have gradually added cost, time, sustainability, facilities management and geo-spatial locating variables. Work continues to progress on improved visualisation and simulation abilities. Common themes in the breakout sessions alluded to "Increased knowledge requirements" and "Increased levels of collaboration and communication". A specific problem for small construction contractors concerned the cost and resourcing of hardware and data storage requirements e.g. This is a major issue because if you're passing around a model that is, say, half a gigabyte, even with very high bandwidth communications, you can't pass that around very much and just archiving that sort of information is incredibly difficult.

It was therefore apparent that the higher the level of information technology, the higher the level of business resourcing needs (including hardware, software and technical expertise). In adding to this, it was evident that small construction contractors needed to learn and understand project BIM specific platforms and data compliance standards in order to collaborate and check the consistency of data, thus creating further training and resourcing needs.

Here, it is relevant to point out that many small construction contractors do not see their primary role as designing or facilitating information flows but rather they are typically receivers and adaptors of information for the purpose of constructing things; they are often towards the end of the information chain and subsequently information often has a one way directional flow. As such, they have less express interest in the big picture of BIM; a smaller perspective of what they will get from it; and a smaller budget to commit to it. In real terms, BIM may confront their preferred business model of maintaining low operating overheads to remain competitive. BIM tends to contest this premise as it is not easily scalable at present. Instead, it potentially creates a new layer of expertise within small contracting businesses. Further, BIM may only be used on a limited number of the business's projects and so dedicated BIM staff may be underutilised at a broader organisational level. Of course there is also the likely problem that this layer of BIM expertise may reside within a single person which means that operations become pivotal around a new but relatively unknown area of expertise, thus creating 
unwanted operational risks. As mentioned by some during the breakout sessions, it is also unclear who is the right person (people) to hire in terms of the expertise that will most benefit the business's operations e.g.

The most common story I get is builders say, how are we going to do this? Answer, I know, we'll go and find someone who's an expert in [design authoring software] - apologies. They're not the right people, they're not builders. They don't actually know how to do it(...) but they drive a solution that's in the architectural world. They're not driving a solution that's in the construction management world.

\subsection{Risks divested down the supply chain}

A feature of discussion from the workshop concerned the accuracy of BIM information provided down the supply chain, to those involved in construction contrcating. Comments suggest that designs often lack continuity and appropriate detail for construction. Many instances of this were put forward including the following:

Architects don't currently have continuity between their sketch design, detail design, construction documentation. If architects can't get continuity within their own profession and their own office, how can they get continuity anywhere else.

So if you have incomplete models, models with missing information and a missing level of detail, I think that causes problems. If a model is done correctly, clearly it helps mitigate risk. If it is the other way around, then you probably enhance the chances of encountering a problem.

Certainly I think people on the table are very critical and think that it's an important issue about completeness of the model and who is accountable for if anything goes wrong and it's implication on the various contractual issues that are on the table.

If you're relying on models from architects, they're probably not going to be done at a suitable standard and there needs to be a lot of work at that front end around integrating - which gets us onto integrated project delivery.

For the understanding or for the people that are working inside these processes, they must have a basic understanding inside the usage of BIM, how processes are constructed, how processes are developed on the construction site and even how progress is reported in the construction industry.
The main point from these quotations is that those undertaking the design process do not necessarily have a full understanding of the ramifications concerning how their information will be used further down the supply chain i.e. for trade level construction purposes. The previously mentioned point about lack of confidence in the accuracy of information may mean that contractors are ultimately not prepared to make serious usage of it.

It is also unclear who is responsible for inaccurate information. The lack of fully detailed design documentation is certainly not new but it does raise the obvious issue that a contractor is unlikely to place confidence in a BIM that is not formally linked to the contract and is suspected of having inconsistent or inaccurate information. It really only leaves contractors with the choice of doing their own exploration, investigation and checking of data. Even so, the previously discussed problems of resourcing, standards protocols and training, creates an obvious disincentive for this to occur in real terms. It also tends to mean that subcontractors simply place stronger faith in traditional 2-D documentation, which they are more used to searching for mistakes and emissions.

\section{Conclusion}

The findings from the study are consistent with other work in the area but add context and qualifying statements that assist understanding. For instance, whilst BIM has a degree of uptake among design professionals on Australian construction projects, there currently appears to be relatively low uptake among general construction contractors beyond design management and (some) program planning activities. The level of uptake appears even lower for small subcontracting businesses being the main target of interest arising from this paper. They seem to represent the weakest link in the supply chain concerning BIM uptake.

A general theme from the literature review - as captured by Bew and Underwood [16] - was that for BIM implementation to be successful, it must be collaborative across the entire supply chain but it must concurrently make sense for businesses to be involved in such technology; it must be realistic relative to that business's current capabilities. The findings from this study suggest that BIM is not particularly realistic for small subcontract businesses in Australia at this point in time, thus preventing full realisation of the collaborative benefits that BIM potentially offers

The question for small construction contractors is therefore at what rate should they get involved, and what is it worth to them? There is currently a basic problem between the economies of scale presented by BIM and the apparent disconnect for small subcontract 
enterprises in fitting in with this scale of operation. For instance, BIM aims to offer a decreasing cost per unit of information output but this does not seem to necessarily convert to reduced costs for small subcontract businesses. Instead, BIM appears to require significant resourcing including big learning curves, big files, big hardware, big human resourcing commitments, big design management involvement and big ITC involvement. This level of "big" commitment is essentially counter to the basic premise of small enterprises whose modus operandi generally revolves around low overheads and low investment. In the short term, the inability of small businesses to absorb higher fixed costs within their operating overheads means that BIM will likely come at an additional cost to project specific budgets - a factor that is not necessarily seen as a value-add in terms of tangible outputs. A key point here is simply that unlike architects, consultants and project managers who to some extent make fees by creating and managing information flows, trade based sub-contractors ostensibly make income and add value via the tangible outputs they deliver.

A further conclusion from the research is the general push by some to mandate and force BIM usage along the entire supply chain. Some may not have full understanding of the capacity of the supply chain to actually undertake this in a way that is genuinely beneficial to the industry. For instance, correctly set regulation can help lead BIM progress but incorrectly set regulation may only serve to create dysfunctional market mechanisms. With this in mind, trying to force training and technical advancement is one way of attempting to progress small businesses but not the only way and not necessarily the easiest way. In the worst cases scenario it may only promote competency in the likes of large BIM authoring software which ultimately has little relevance to the needs of small trade based subcontractors - they have greater interest in simply manipulating, detailing or extracting already authored design information.

Where BIM would benefit small subcontract businesses is in software applications that directly assist productivity onsite during the physical execution of the work. To name but a few instances, they require construction accurate information relating to assembly details, management of site quality control, checking of orders, making orders, sorting materials deliveries, marking where materials should go, recording completed work, obtaining site instructions and dealing dynamically with site identified safety issues.

It is therefore worth re-thinking or at least adapting selective BIM implementation to suit the specific needs of small contracting businesses. Here, greater attention should be placed on the scalability of BIM applications and consideration of one way information flows. For instance, rather than using high end, expensive and complicated software applications, the focus should move towards smaller, simpler and trade package specific applications. Consequently, a "touch the BIM lightly" approach should prevail. This should target low levels of BIM proficiency, based around extraction of information and relatively limited return information to the master BIM. In many ways, such an approach would be similar to many smartphone or tablet "apps" which typically exhibit:

- free or very low cost,

- quick, simple and intuitive learning

- an emphasis on user needs and how information will be used

- a focus on doing relatively small tasks well

- (Occasionally) providing output files that can be transferred to more comprehensive software.

Of note, this would go some way to addressing Oluwole's point [29] that software costs can account for as much as 55 percent of total BIM implementation costs. Further, it would circumvent related resourcing requirements such as software training costs and the need for software specialists. Such an approach pushes the virtues of a simplified approach to BIM implementation for targeted users.

In a sense, this would support the democratisation of BIM (by making it available to a greater cross section of the supply chain) and would concurrently reduce the potential onset of learned helplessness among those who to date, have seen it as being too difficult to implement.

Despite the potential benefits of such an approach, it would also seem that those higher up in the supply chain must commit more fully to the accuracy of information passed down the chain in order to realistically provide improved efficiency and the mitigation of risk to small contracting businesses.

\section{References}

[1] Eastman, C., Teicholz, P., Sacks, R., and Liston, K., BIM Handbook. 2 ed., New Jersey: John Wiley and Sons, 2011.

[2] [a]Grilo, A. and Jardim-Goncalves, R., Value proposition on interoperability of BIM and collaborative working environments. Automation in Construction, 19(5): 522-530, 2010; [b]Steel, J., Drogemuller, R., and Toth, B., Model interoperability in building information modelling. Software and Systems Modeling: 1-11, 2009. 
[3] Zhou, W., Whyte, J., and Sacks, R., Construction safety and digital design: A review. Automation in Construction, 22: 102-111, 2012.

[4] Sacks, R., Radosavljevic, M., and Barak, R., Requirements for building information modeling based lean production management systems for construction. Automation in Construction, 19(5): 641655, 2010.

[5] Zollinger lii, W.R., Sutton, D.L., Montler, G., and Seifried, M.M., BIM: Sharing Project Data Reduces Conflict. AACE International Transactions: BIM.03.1BIM.03.18, 2010.

[6] Azhar, S., Carlton, W.A., Olsen, D., and Ahmad, I., Building information modeling for sustainable design and LEED $^{\circledR}$ rating analysis. Automation in Construction, 20(2): 217-224, 2011.

[7] Benjaoran, V. and Bhokha, S., Enhancing visualization of 4D CAD model compared to conventional methods. Engineering, Construction and Architectural Management, 16(4): 392, 2009.

[8] Lipman, R., Palmer, M., and Palacios, S., Assessment of conformance and interoperability testing methods used for construction industry product models. Automation in Construction, In Press, Corrected Proof,

[9] [a]McCuen, T.L., Scheduling, Estimating, and BIM: a Profitable Combination. $A A C E$ International Transactions: BIM11, 2008; [b]Popov, V., Juocevicius, V., Migilinskas, D., Ustinovichius, L., and Mikalauskas, S., The use of a virtual building design and construction model for developing an effective project concept in 5D environment. Automation in Construction, 19(3): 357-367, 2010.

[10] Rekola, M., Kojima, J., and Makelainen, T.M., Towards Integrated Design and Delivery Solutions: Pinpointed Challenges of Process Change. Architectural Engineering and Design Management, 6: 264, 2010.
[11] Froese, T.M., The impact of emerging information technology on project management for construction.

Automation in Construction, 19(5): 531538, 2010.

[12] Singh, V., Gu, N., and Wang, X., A theoretical framework of a BIM-based multi-disciplinary collaboration platform. Automation in Construction, 20(2): 134144, 2011.

[13] Porwal, A. and Hewage, K.N., Building Information Modeling (BIM) partnering framework for public construction projects. Automation in Construction, 31(0): 204-214, 2013.

[14] London, K. and Chen, J., Civil Construction Supply Chain Management Policy to Support Collaborative Relationships in Public Sector Procurement. Collaborative Relationships in Construction. WileyBlackwell. 197-223, 2009.

[15] Gu, N., Singh, V., Taylor, C., London, K., and Brankovic, L., BIM adoption: expectations across disciplines. Handbook of Research on Building Information Modeling and Construction Informatics: Concepts and Technologies, Information Science Reference, Hershey, PA: 501-20, 2009.

[16] Bew, M. and Underwood, J., Delivering BIM to the UK Market, in Handbook of research on building information modeling and construction informatics: Concepts and technologies, IGI Global: Pennsylvania. 30-64, 2010.

[17] Sebastian, R., Changing roles of the clients, architects and contractors through BIM. Engineering, Construction and Architectural Management, 18(2): 176187, 2011.

[18] Clifford, M., Nilakant, V., and Hamilton, R., Management succession and the stages of small business development. International Small Business Journal, 9(4): 43-55, 1991.

[19] Atkins, M. and Lowe, J., Sizing up the small firm: UK and Australian experience. 
International Small Business Journal, 15(3): 42-55, 1997.

[20] ABS, Australian Small Business ket statistics and analysis, in 8772.0: Canberra, 2012.

[21] ABS, Private sector construction industry: Canberra, 2013.

[22] Benjaoran, V., A cost control system development: A collaborative approach for small and medium-sized contractors. International Journal of Project Management, 27(3): 270-277, 2009.

[23] Kaplan, J., Small business is big business. Practice Periodical on Structural Design and Construction, 1(3): 78-78, 1996.

[24] Group, I.a.B.S., The 2004 construction industry survey: the whole kingdom: Bangkok, 2005.

[25] Gledson, B., Henry, D., and Bleanch, P., Does size matter? Experiences and perspectives of BIM implementation from large and SME construction contractors. 2012.

[26] Yan, H. and Damian, P. Benefits and barriers of building information modelling. in 12th International Conference on Computing in Civil and Building Engineering 2008. 2008.

[27] Greenwood, D., Lewis, S., and Lockley, S., Contractual issues in the total use of building information modelling. 2010.

[28] Takim, R., Harris, M., and Nawawi, A.H., Building Information Modeling (BIM): A New Paradigm for Quality of Life Within Architectural, Engineering and Construction (AEC) Industry. ProcediaSocial and Behavioral Sciences, 101: 2332, 2013.

[29] Oluwole, A.O., Modelling the costs of corporate implementation of building information modelling. Journal of Financial Management of Property and Construction, 16(3): 211-231, 2011.

[30] ArayıCI, Y. and Coates, P., Operational Knowledge for BIM Adoption and Implementation for Lean Efficiency Gains.
Journal of Entrepreneurship and Innovation Management, 1(2): 1-20, 2013.

[31] Arayici, Y., Coates, P., Koskela, L., Kagioglou, M., Usher, C., and O'Reilly, K., BIM adoption and implementation for architectural practices. Structural Survey, 29(1): 7-25, 2011.

[32] Anderson, A., Marsters, A., Dossick, C.S., and Neff, G., Construction to Operations Exchange: Challenges of Implementing COBie and BIM in a Large Owner Organization, in Construction Research Congress, ASCE. 688-697, 2012.

[33] Harris, R., McAdam, R., McCausland, I., and Reid, R., Levels of innovation within SMEs in peripheral regions: the role of business improvement initiatives. Journal of Small Business and Enterprise Development, 20(1): 102-124, 2013.

[34] Cicourel, A.V., Method and Measurement in Sociology. New York: Free Press of Glencoe, 1964.

[35] Boyatzis, R.E., Transforming qualitative data: Thematic analysis and code development, Thousand Oaks, CA: Sage, 1998. 